\title{
ASPECTOS ANATOPATOLÓGICOS DA INTOXICAÇÃO CRÔNICA POR COBRE EM OVINO
}

\author{
(Anatomopathological aspects of acute copper poisoning in sheep)
}

\begin{abstract}
Arthur Colombari Cheng, Juliana das Chagas Goulart, Carolina Fontana, Eduardo Michelon do Nascimento, Geane Maciel Pagliosa, Aline de Marco Viott
\end{abstract}

Universidade Federal do Paraná, Palotina, Paraná, Brasil.

*Correspondência: aarthurcheng@gmail.com

RESUMO: O cobre é um metal pesado essencial ao organismo, atuando nas células em numerosos processos biológicos essenciais, como respiração celular, síntese de melanina, metabolismo do ferro, antioxidante e biossíntese de neurotransmissor. No organismo, o cobre sérico está ligado à ceruloplasmina, e o cobre hepático é ligado à metalotioneína e armazenado em lisossomos. O excesso de cobre leva à produção de radicais livres, que inicia reações de peroxidação lipídica destrutivas que afetam a mitocôndria e outras membranas celulares (STALKER \& HAYES, 2007). As manifestações clínicas caracterizam-se por dor abdominal, diarreia, icterícia, anorexia, desidratação e choque. Elevados níveis de cobre sérico pode levar a hemólise intravascular (CULLEN \& BROWN, 2013). Relata-se um caso de intoxicação aguda por cobre em um ovino diagnosticado pelo Laboratório de Patologia Veterinária (LPV) da Universidade Federal do Paraná - Setor Palotina. Um ovino, Santa Inês, fêmea, de três anos, proveniente de propriedade cujo animais passaram a receber ração de suíno. O proprietário relatou que após 10 dias de do início da alimentação cerca de $17 \%$ dos animais foram a óbito. Na macroscopia, observou-se fígado difuso e acentuadamente pálido com moderada hepatomegalia, moderada esplenomegalia, hemoglobinúria e rins de cor vermelho escura. Na microscopia, no rim observou-se no interstício hemorragia multifocal a coalescente acentuada principalmente em região de medular. Nos túbulos renais havia aumento da eosinofilia citoplasmática com picnose e carriorexia nuclear multifocal a coalescente acentuada, com desprendimento de algumas células para o lúmen (necrose tubular aguda). No interior de túbulos multifocais havia moderada presença de material amorfo, avermelhado, homogêneo que tendiam a formar cilindros (cilindros hemoglobinicos). No fígado, havia necrose individual de hepatócitos e nas tríades portais observava-se moderado infiltrado inflamatório linfohistiocitário e neutrofílico (hepatite) e moderada presença de fibroblastos com formação de pequenas pontes de tecido conjuntivo fibroso (fibrose). Os cortes histológicos de fígado e rim foram moderadamente positivos para a coloração de rodanina. Esta coloração é utilizada para evidenciar depósitos de cobre em cortes histológicos. Diante do presenta caso, o histórico clínico e os achados anatopatológicos corroboram para o diagnóstico de intoxicação crônica por cobre. Logo, por se tratar de uma afecção que acarreta a grandes prejuízos econômicos culminando em diminuição da produtividade devido seu comprometimento sistêmico, ressalta-se a importância deste levantamento epidemiológico, contribuindo na prevenção da doença.

Palavras-chaves: cilindro hemoglobinicos, hemoglobinúria, nefrose tubular aguda, rodanina.

\section{Referências}

CULLEN, J. C; BROWN, D. L. Sistema Hepatobiliar e Pâncreas Exócrino. In: ZACHARY, J. F; MCGAVIN, M. D. Bases da Patologia em Veterinária. 5. ed. São Paulo: Elsevier, 2013. p. 412-470.

STALKER, M.J.; Hayes, M.A. Liver and biliary system. In.: MAXIE, M.G. (Ed.). Jubb, Kennedy \& Palmer's pathology of domestic animals. Philadelphia: Elsevier, 2007. p.369-381. 